\title{
Genetic analysis of malformations causing perinatal mortality
}

\author{
I D YOUNG*, A B RICKETT*, AND M CLARKE† \\ From the Departments of Child Health* and Community Healtht, University of Leicester, \\ Leicester LE2 $7 L X$.
}

SUMMARY An analysis of congenital malformations, other than neural tube defects, which have contributed to perinatal mortality in Leicestershire is presented for the years 1976 to 1982 inclusive. Chromosomal, single gene, or polygenic inheritance accounted for $67 \%$ of cases.

Several studies have indicated that congential malformations account for a substantial proportion of babies dying in the neonatal and perinatal periods. ${ }^{1-3}$ As other causes of perinatal death continue to be reduced, attention will focus increasingly on the group of babies with congenital malformations, and in particular on those other than neural tube defects, which are unlikely to be amenable to detection through relatively simple prenatal diagnostic screening.

A comprehensive survey of perinatal mortality was initiated in Leicestershire in $1976 .{ }^{45}$ The present study was undertaken (1) to review the spectrum of malformations, other than neural tube defects, which result in perinatal death; (2) to determine the proportion of malformations in which genetic factors are implicated; (3) to consider ethnic differences, since it is known that lethal congenital malformations are more common in Asians than in non-Asians in Leicestershire ${ }^{6}$; and (4) to consider the theoretical potential effect on perinatal mortality of a vigorous prenatal diagnostic programme.

\section{Methods}

Details of all malformed babies, other than those with isolated neural tube defects, dying during the perinatal period in Leicestershire in the years 1976 to 1982 inclusive were obtained from the records of the Leicestershire Perinatal Mortality Survey. This ongoing survey, which has been described in detail elsewhere ${ }^{4}$ records information about all babies dying in the perinatal period. The survey is organised through the Department of Community Health in collaboration with the Department of Obstetrics and Gynaecology.

Received for publication 23 October 1984

Revised version accepted for publication 2 January 1985.
All perinatal deaths in the county are notified to the midwife who co-ordinates the survey. Subsequently the mother is interviewed and a questionnaire completed. Data are cross checked by reference to the Area Health Authority's notification system of births and deaths and also by obtaining information provided to the Registrar General through certification.

For the purposes of the present study attempts were made to review the original hospital records of all malformed babies ascertained through the Perinatal Mortality Survey, along with necropsy reports, radiographs, and clinical photographs.

Babies were only included in the study if it was clear from their records that death was due primarily to a malformation. Thus, babies who probably died as a result of problems associated with prematurity or birth asphyxia, but who also had a relatively minor malformation such as a small ventricular septal defect, were excluded. In three babies the cause of death was ascribed to congestive cardiac failure associated with a large patent ductus arteriosus and, although a patent ductus can be regarded as physiological in the newborn, the sequence of events in these babies was not consistent with normal physiological variation. Consequently they have been included in the study.

\section{Results}

ANALYSIS OF LETHAL MALFORMATIONS

During the years 1976 to 1982 inclusive, 147 babies died during the perinatal period in Leicestershire as the result of congenital abnormality, excluding isolated neural tube defects. The perinatal mortality rate fell during this time from 21.1 per 1000 in 1976 to 11.2 per 1000 in 1982 . However, the number of 
babies dying as the result of malformation remained relatively constant, as indicated in table 1 .

It was possible to review the hospital records of 141 of the 147 babies in the study, 108 of whom had undergone necropsy. Chromosome analysis had been attempted in 48 of these babies, successfully in 39 instances. Clinical photographs of 18 babies were available for review. A total of 119 babies was liveborn and 22 stillborn.

\section{Chromosomal abnormalities (24 babies)}

An abnormal karyotype was detected in 23 babies, as summarised in table 2 . This table includes one additional baby for whom a chromosome result was not obtained. The clinical features were consistent with Patau's syndrome and subsequent studies showed a maternal karyotype of $45, \mathrm{XX}, \mathrm{t}(13 \mathrm{q} ; 14 \mathrm{q})$. This karyotype was also found in the mother of a baby with a proven unbalanced Robertsonian translocation, 46,XY, $-14,+t(13 q ; 14 q)$. Details of the child with trisomy 9 have been published elsewhere. ${ }^{7}$ The father of one of the babies with trisomy $18 \mathrm{had}$ a child with trisomy 21 from a previous marriage.

\section{Single system involvement ( 73 babies)}

Those babies showing a malformation or dysplasia affecting primarily a single system are summarised in table 3.

TABLE 1 Perinatal deaths due to malformations in Leicestershire 1976 to 1982.

\begin{tabular}{lllll}
\hline Year & $\begin{array}{l}\text { Malformed } \\
\text { perinatal deaths } \\
\text { (excluding NTD) }\end{array}$ & $\begin{array}{l}\text { Total } \\
\text { perinatal } \\
\text { deaths }\end{array}$ & $\begin{array}{l}\text { Total } \\
\text { births }\end{array}$ & $\begin{array}{l}\text { Malformed } \\
\text { deaths per } \\
1000\end{array}$ \\
\hline 1976 & 18 & 230 & 10875 & 1.66 \\
1977 & 24 & 190 & 10835 & 2.22 \\
1978 & 23 & 196 & 11060 & $2 \cdot 08$ \\
1979 & 23 & 172 & 11754 & 1.96 \\
1980 & 22 & 151 & 12346 & 1.78 \\
1981 & 21 & 118 & 11791 & 1.78 \\
1982 & 16 & 130 & 11557 & 1.38 \\
\hline
\end{tabular}

TABLE 2 Study babies with chromosome abnormalities.

\begin{tabular}{lc}
\hline Type of abnormality & Number ascertained \\
\hline Trisomy 9 & 1 \\
Trisomy 13 & 5 \\
Trisomy 18 & 9 \\
Trisomy 21 & 4 \\
Unbalanced Robertsonian & 2 \\
translocation 13q:14q* & 1 \\
Triploidy & 1 \\
18p- & 1 \\
Other & 24 \\
Total & \\
\hline
\end{tabular}

*Includes one presumptive case, see text.
TABLE 3 Study babies with single system involvement.

\begin{tabular}{lc}
\hline Cardiac & \\
Hypoplastic left heart & 3 \\
Pulmonary atresia & 2 \\
Transposition of the great vessels & 2 \\
Coarctation of the aorta & 3 \\
Patent ductus arteriosus & 1 \\
Total anomalous pulmonary venous drainage & 1 \\
Isomerism & 1 \\
Persistent fetal circulation & 1 \\
Type unknown & 9 \\
Complex & 31 \\
Total & \\
Renal & \\
Bilateral agenesis & 8 \\
Polycystic/dysplastic kidneys & 4 \\
Urethral obstruction & 2 \\
Total & 14 \\
Pulmonary & \\
Diaphragmatic hernia/agenesis & 10 \\
Pulmonary hypoplasia & 1 \\
Total & 11 \\
Gastrointestinal & \\
Gastroschisis & \\
Exomphalos & \\
Achalasia & 1 \\
Total & 1 \\
Cerebral & 1 \\
Iniencephaly & 3 \\
Lissencephaly & \\
Holoprosencephaly/cyclops & \\
Total & \\
Skeletal & \\
Osteogenesis imperfecta congenita & \\
Campomelic dysplasia & 2 \\
Saldino-Noonan syndrome & 1 \\
Thanatophoric dysplasia & \\
Other & 2 \\
Total & 1 \\
\hline & 3 \\
\hline
\end{tabular}

Cardiac ( 31 babies) In 25 cases the diagnosis was confirmed at necropsy, which was refused in the remaining six cases. The diagnosis was based on catheter or echocardiograph studies in five babies. The one remaining baby died before a precise diagnosis could be established. One couple had a previous child with a corrected transposition.

Renal (14 babies) There were eight cases, all male, who had bilateral renal agenesis, the diagnosis being proven in seven at necropsy. Cystic renal disease was found in six babies, three of whom had infantile polycystic disease (type I in Potter's classification ${ }^{8}$ ), two had urethral obstruction (Potter type IV), and one had histological changes of bilateral dysplasia (Potter type II).

Pulmonary (11 babies) Herniation of abdominal contents into the thorax occurred in 10 babies who were otherwise normally formed. In seven a defect in the diaphragm was documented at surgery or 
necropsy. Three babies were documented as having complete agenesis of the left hemidiaphragm at necropsy. One of these families had had a previous child who died shortly after birth with the same condition. The baby who died with pulmonary hypoplasia had normal kidneys.

Gastrointestinal (three babies) The baby described as having achalasia had a grossly dilated oesophagus at necropsy. Histology showed normal ganglion cells but very little miscle. The babies with exomphalos and gastroschisis were both very premature and macerated.

Cerebral (five babies) Two babies had holoprosencephaly, one with a median cleft lip in whom chromosomes were normal, and the other with cyclops in whom chromosome studies were unsuccessful. In the baby with cyclops abnormalities were limited to the brain. The baby with lissencephaly had an abnormal facial appearance with low set ears and epicanthus. Chromosomes were normal.

Skeletal (nine babies) The diagnoses listed in table 3 are based on review of photographs and $x$-rays in two babies, review of photographs alone in two babies, and review of $x$-rays alone in two babies. In the remaining three cases no information could be obtained which would permit a definite diagnosis.

\section{Miscellaneous group (44 babies)}

The diagnoses in this group are summarised in table 4.

Amniotic bands This was the probable diagnosis in five babies, four of whom had a very large exomphalos or gastroschisis along with limb and spinal abnormalities. The fifth baby had a large encephalocele and missing anterior chest wall.

Twin-twin disruptions There were four sets of twins, one of whom was normally formed and the other grossly abnormal. One baby showed absence of

TABLE 4 Causes of death other than chromosomal and single organ involvement.

\begin{tabular}{lc}
\hline Amniotic bands & 5 \\
Twin-twin disruption & 4 \\
VATER association & 3 \\
Cloacal abnormality & 2 \\
Recessive syndromes & \\
Meckel's syndrome & 6 \\
Roberts's syndrome & 1 \\
Hydrops fetalis & 1 \\
Pterygium syndrome & 2 \\
Multiple congenital abnormalities. cause unknown & 20 \\
\hline
\end{tabular}

facial differentiation with no ears or neck, short upper limbs, and a large skin defect involving the thorax and abdomen. Another had a missing cranial vault, anophthalmia, and exomphalos. Two babies consisted of only a pear-shaped body with lower limbs but no upper limbs or head.

\section{Vater association (three babies)}

Cloacal anomalies (two babies) One showed cloacal exstrophy and the other persistence of the cloaca.

Other recessive syndromes (10 babies) Six babies had Meckel's syndrome, of whom five were born to Hindu parents as documented elsewhere. ${ }^{9}$ One baby had hydrops fetalis with normal haemoglobin, bones, and chromosomes. The parents subsequently had another similarly affected child. The baby with Roberts's syndrome already had an affected surviving older sib. Two sibs born to first cousin Asian parents had a short neck, scoliosis, and webbing of the elbows, hips, and knees, abnormalities consistent with a lethal pterygium syndrome. ${ }^{10}$

Multiple congenital abnormalities (cause unknown) There were 20 babies in the study who had abnormalities which cannot be readily classified, either because investigations were incomplete, or because the abnormalities as documented do not conform to any disorder or syndrome known to the authors.

THE GENETIC CONTRIBUTION TO PERINATAL MORT A L ITY

Those babies whose abnormalities were likely to have been at least partially genetic in origin are summarised in table 5, from which it can be seen that genetic factors can be implicated in 94 of the $141(67 \%)$ babies in the study. Chromosomal abnormalities accounted for $17 \%$, established autosomal recessive inheritance for $12 \%$, possible recessive inheritance for $6.4 \%$, and multifactorial or aetiologically heterogeneous disorders for $31.2 \%$.

If a recurrence risk of $0 \%$ is assumed for the remaining 47 cases, a composite or average recurrence risk of $5.6 \%$ for the entire study group is obtained. This figure reduces to $4 \cdot 3 \%$ if the cases with possible autosomal recessive inheritance are assumed to have a recurrence risk of $5 \%$ rather than $25 \%$.

ETHNIC DIFFERENCES

Babies born to parents originating from the Indian subcontinent accounted for 28 of the study cases, that is, 2.9 per 1000 deliveries $(n=9588)$. The comparable rate among non-Asian babies was 1.6 
TABLE 5 Cases with a genetic component.

\begin{tabular}{|c|c|c|}
\hline & Number & $\begin{array}{l}\text { Recurrence } \\
\text { risk }(\%)\end{array}$ \\
\hline \multicolumn{3}{|l|}{ Chromosomal } \\
\hline -Trisomy $9,13,18,21$ & 19 & $1 \cdot 3^{11}$ \\
\hline Translocation $13 \mathrm{q}: 14 \mathrm{q}$ & 2 & $1 \cdot()^{12}$ \\
\hline Other & 3 & $1 \cdot 3^{11}$ \\
\hline Total & 24 & \\
\hline \multicolumn{3}{|l|}{ Autosomal recessive } \\
\hline \multicolumn{3}{|l|}{ Definite } \\
\hline Infantile polycystic kidneys & 3 & \\
\hline Diaphragmatic agenesis (sib affected) & 1 & \\
\hline Campomelic dysplasia & 2 & \\
\hline Saldino-Noonan syndrome & $\overline{1}$ & \\
\hline Meckel's syndrome & 6 & \\
\hline Roberts's syndrome & 1 & \\
\hline Hydrops fetalis & 1 & $25 \cdot 0$ \\
\hline Pterygium syndrome & 2 & \\
\hline \multicolumn{3}{|l|}{ Possible } \\
\hline Renal dysplasia ${ }^{13}$ & 1 & \\
\hline Diaphragmatic agenesis ${ }^{14}$ & 2 & \\
\hline Lissencephaly 15 & $\overline{1}$ & \\
\hline Osteogenesis imperfecta congenita ${ }^{16} 17$ & 2 & \\
\hline Other lethal dwarfism & 3 & \\
\hline Total & 26 & \\
\hline \multirow{2}{*}{\multicolumn{3}{|c|}{ Multifactorial/heterogeneous }} \\
\hline & & \\
\hline Hypoplastic left heart & 8 & $2 \cdot 2$ \\
\hline Pulmonary atresia & 3 & $1 \cdot 3$ \\
\hline Transposition & 2 & 1.7 \\
\hline Coarctation & 2 & $1 \cdot 8$ \\
\hline Patent ductus arteriosus & 3 & $3 \cdot 5$ \\
\hline Total anomalous pulmonary venous drainage & 1 & $1 \cdot 0$ \\
\hline Complex (including one unknown) & 9 & $1 \cdot 0$ \\
\hline Isomerism & 1 & $4 \cdot 65^{14}$ \\
\hline Persistent fetal circulation & 1 & $?^{*}$ \\
\hline Two affected babies & 1 & $10 \cdot 0^{211}$ \\
\hline \multicolumn{3}{|l|}{ Other } \\
\hline Bilateral renal agenesis & 8 & $3 \cdot 0^{21}$ \\
\hline Iniencephaly & 2 & $5 \cdot 0$ \\
\hline Holoprosencephaly/cylops & 2 & $6 \cdot 0^{22}$ \\
\hline Thanatophoric dysplasia & 1 & $2 \cdot()^{33}$ \\
\hline Total & 44 & \\
\hline
\end{tabular}

*This disorder has recently been described in sibs. ${ }^{24}$

per 1000 deliveries (113 cases, $n=70630$ ). Of these 28 Asian babies, nine had a definite autosomal recessive syndrome (five Meckel's, two pterygium, one hydrops, one polycystic kidneys) and two had a possible recessive disorder (one osteogenesis imperfecta congenita and one short limbed dwarf). If definite and possible recessive syndromes are excluded from both the Asian and non-Asian groups, rates of 1.8 and 1.4 per 1000 deliveries are obtained. No single malformation or group of malformations accounted for the remaining excess in the Asian babies.

THE POTENTIAL FOR PREVENTION

How many abnormalities could have been detected during the first half of pregnancy by either (1) consideration of the family history followed by appropriate prenatal diagnostic tests or (2) 'routine' screening tests of pregnancy?
(1) Six babies had a notable family history. These were the baby with trisomy 18 whose father had a child with trisomy 21 in a previous marriage, the baby with complex congenital heart disease (tricuspid atresia, transposition, hypoplastic aorta), who had an older sib with corrected transposition, and those babies who had an older sib with an autosomal recessive disorder, that is, diaphragmatic agenesis, Meckel's syndrome, pterygium syndrome, and Roberts's syndrome.

(2) Two babies might have been detected by prenatal diagnostic screening. These were a baby with trisomy 18 whose mother was aged 38 years, and a baby with renal dysplasia whose mother had a high serum alphafetoprotein (amniocentesis was unsuccessful). The baby with exstrophy of the cloaca also had a high maternal serum alphafetoprotein. This baby was, however, one of twins.

Thus a vigorous prenatal diagnostic programme assuming total parental compliance would at most have prevented the birth of eight of the study babies. If sophisticated diagnostic ultrasound, as exists presently at centres of excellence, had been available throughout the period of the study as a routine screening procedure, then many of the more severe cardiac, diaphragmatic, renal, skeletal, and possibly cerebral abnormalities could have been detected. Clearly the logistics of offering such a service are considerable.

\section{Discussion}

Malformations accounted for $18 \%$ of perinatal deaths in the United Kingdom in $1958,{ }^{25} 25 \%$ in $1970,{ }^{25}$ and $34 \cdot 1 \%$ in Avon in 1976 to $1979 .{ }^{26}$ It is probable that their relative importance as a cause of perinatal mortality will continue to increase in parallel with progress in fetal and neonatal care. This will apply particularly to malformations other than neural tube defects. During the short course of this survey the contribution of malformations other than neural tube defects to perinatal mortality in Leicestershire rose from $10 \%$ in 1976 to 1977 to $14.9 \%$ in 1981 to 1982 .

The genetic contribution to lethal malformations has been noted previously. In Vancouver $47 \cdot 3 \%$ of malformed stillbirths were wholly or partly genetic in origin. ${ }^{27} 28$ In Seattle a comparable figure of $79.5 \%$ was obtained, ${ }^{29}$ this high figure possibly reflecting a selected teaching hospital population. In a Swedish study, $25 \%$ of malformations causing perinatal death could be attributed to chromosomal or definite single gene abnormalities. ${ }^{30}$

The values obtained for Leicestershire may not be entirely representative of the United Kingdom since 
during the period of the study, $12 \%$ of all births in the county were to mothers of Asian origin. These births accounted for a disproportionate $19.9 \%$ of malformed perinatal deaths, excluding neural tube defects. This excess is explained largely, but not completely, by disorders showing autosomal recessive inheritance, which can be attributed to (1) the high incidence of Meckel's syndrome in the Hindu community, ${ }^{9}$ and (2) the high incidence of consanguinity in the Muslim community. Review of the hospital records indicates that at least three of the Asian babies with definite autosomal recessive disorders were born to first cousin parents.

Leicestershire is a relatively compact county with a population of approximately 833000 and medical services centred on two teaching hospitals in Leicester. This structure facilitates the collection of data. In a review such as this the completeness of enumeration of cases is essential. Comparison between the data reported by the Registrar General on death certificates and data recorded in the Leicestershire Perinatal Survey shows almost total agreement. Unfortunately these high standards have not always applied to the extent of the investigations carried out on each abnormal baby. It has been noted previously that for many reasons assessment of the malformed stillborn or dead neonate is not always complete ${ }^{31} 32$ and certainly this applies to several of the cases in this study, particularly at its start. Part of the problem rests with the storage and retrieval of records, and in particular $x$-rays, which are routinely destroyed after five years.

Review of the study cases indicates that even with the most comprehensive prenatal diagnostic programme, assuming total parental commitment, only a very small proportion of these cases could have been 'prevented'. When routine prenatal diagnostic ultrasound becomes widely available as a screening procedure at a level of sophistication which will reliably permit the detection of cardiac, diaphragmatic, renal, and skeletal abnormalities, this will have a significant impact in reducing the contribution of malformations to perinatal mortality. Until that time this contribution is unlikely to diminish. In view of the implications for future pregnancies the strongest possible case can be made for the full assessment of every malformed baby dying in the perinatal period, so that those at high risk may be forewarned while those at low or negligible risk may be reassured. The need for photography, radiology, cytogenetics, and careful necropsy cannot be over-emphasised.

The authors wish to thank Elizabeth Mason, Ivy Rushby, and Sue Kenney for their help in this study, and in particular Professor John MacVicar for his support and encouragement. The Leicestershire Peri- natal Survey is funded by the Leicestershire Health Authority.

\section{References}

' Mcllwaine GM, Howat RCL, Dunn F, Macnaughton MC. The Scottish perinatal mortality survey. Br Med J 1979;ii:1103-6.

2 Confidential inquiry into perinatal deaths in the Mersey region. Lancet 1982;i:491-4.

3 Wood B, Catford JC, Cogswell JJ. Confidential paediatric inquiry into neonatal deaths in Wessex, 1981 and 1982. $\mathrm{Br}$ Med J 1984;288: $1206-8$.

${ }^{4}$ MacVicar J. Perinatal mortality-an area survey. In: Chalmers I, Mcllwaine G, eds. Perinatal audit and surveillance. Proceedings of the eighth study group of the Royal College of Obstetricians and Gynaecologists 1980. London: Royal College of Obstetricians and Gynaecologists, 1980:133-47.

5 Clarke M, Clayton DG. Quality of obstetric care provided for Asian immigrants in Leicestershire. Br Med J 1983;286:621-3.

6 Dhariwal HS. Leicestershire-decline in perinatal mortality. In: McFadyen IR, MacVicar J, eds. Obstetric problems of the Asian community in Britain. A scientific meeting of the Royal College of Obstetricians and Gynaecologists 1981. London: Royal College of Obstetricians and Gynaecologists, 1982:101-8.

7 Williams T, Zardawi I, Quaife R, Young ID. Complex cardiac malformation in a case of trisomy 9. J Med Genet 1985;22:230-3.

${ }^{8}$ Potter EL, Craig JM. Pathology of the fetus and infant. London: Lloyd-Luke, 1975:447-60.

9 Young ID, Rickett AB, Clarke M. High incidence of Meckel's syndrome in Gujarati Indians. J Med Genet 1985;22:301-4.

10 Hall JG. The lethal multiple pterygium syndromes. Am J Mied Genet 1984;17:803-7.

$"$ Stene J, Stene E, Mikkelson M. Risk for chromosome abnormality at amniocentesis following a child with a non-inherited chromosome aberration. Prenat Diag 1984; 4, special issue: 81-95.

12 Boué A, Gallano P. A collaborative study of the segregation of inherited chromosome structural rearrangements in 1356 prenatal diagnoses. Prenat Diag 1984; 4, special issue: 45-67.

${ }^{13}$ McKusick VA. Mendelian inheritance in man. 6th ed. Baltimore: Johns Hopkins University Press, 1983:898-9.

14 Norio R, Kääriäinen H, Rapola J, Herva R, Kekomäki M. Familial congenital diaphragmatic defects. Aspects of etiology, prenatal diagnosis and treatment. Am J Med Genet 1984;17:471-83.

15 Dobyns WB, Stratton RF, Greenberg F. Syndromes with lissencephaly. 1. Miller Dieker and Norman-Roberts syndromes and isolated lissencephaly. Am J Med Genet 1984;18:509-26.

16 Young ID, Harper PS. Recurrence risk in osteogenesis imperfecta congenita. Lancet 1980;i:432.

17 Sillence DO, Barlow KK, Garber AP, Hall JG, Rimoin DL. Osteogenesis imperfecta type II. Delineation of the phenotype with reference to genetic heterogeneity. Am J Med Genet 1984;17:407-23.

${ }^{18}$ Nora $\mathrm{JH}$, Nora AH. Genetics and counseling in cardiovascular disease. Springfield: CC Thomas, 1978:156.

${ }^{19}$ Rose V, Izukawa T, Moës CAF. Syndromes of asplenia and polysplenia. A review of cardiac and non-cardiac malformations in 60 cases with special reference to diagnosis and prognosis. $\mathrm{Br}$ Heart $J$ 1975;37:840-52.

${ }^{20}$ Harper PS. Practical genetic counselling. 2nd ed. Bristol: John Wright, 1984:234.

${ }^{21}$ Carter CO, Evans K, Pescia G. A family study of renal agenesis. $J$ Med Genet 1979;16:176-88.

22 Roach E, Demyer W, Conneally PM, Palmer C, Merritt AD. Holoprosencephaly: birth data, genetic and demographic analyses of 30 families. Birth Defects 1975;XI(2):294-313.

${ }^{23}$ Pena SDJ, Goodman HO. The genetics of thanatophoric dysplasia. Pediatrics 1973;51:104-9.

24 Shohet I, Reichman B, Schibi G, Brish M. Familial persistent pulmonary hypertension. Arch Dis Child 1984;59:783-5. 
25 Perinatal mortality: a continuing collaborative regional survey. $\mathrm{Br}$ Med J 1984:288:1717-20.

26 Mutch LMM. Brown NJ. Speidel BD. Dunn P. Perinatal mortality and neonatal survival in Avon: 1976-9. Br Med J 1981:282:119-22.

27 Poland BJ. Lowry RB. The use of spontaneous abortuses and stillbirths in genetic counselling. Am J Obstet Gynecol 1974:118:322-6.

${ }^{2 x}$ MacLeod PM, Dill F. Hardwick DF. Chromosomes, syndromes, and perinatal deaths: the genetic counselling value of making a diagnosis in a malformed abortus. stillborn and deceased newborn Birth Defects 1979:XV(5A):105-11.

${ }^{29}$ Mueller RF, Sybert VP. Johnson J, Brown ZA. Chen WJ. Evaluation of a protocol for post-mortem examination of stillbirths. N Engl J Med 1983:309:586-90.
30 Gustavson $\mathrm{KH}$, Jorulf $\mathrm{H}$. Recurrence risks in a consecutive series of congenitally malformed children dying in the neonatal period. Clin Genet 1976;9:307-14.

${ }^{31}$ Hall RD. Introductory remarks. Diagnostic approaches to the malformed fetus, abortus, stillborn and deceased newborn. Birth Defects 1979:XV(5A):89-92.

32 Winter RM. The malformed fetus and stillbirth: whose patient? $\mathrm{Br}$ J Obstet Gynaecol 1983;90:499-50.

Correspondence and requests for reprints to Dr I D Young, Department of Child Health, Clinical Sciences Building, PO Box 65, Leicester Royal Infirmary, Leicester LE2 7LX. 